\title{
A Prediction Model for Rubber Curing Process
}

\author{
Shigeru Nozu ${ }^{1}$, Hiroaki Tsuji ${ }^{1}$ and Kenji Onishi ${ }^{2}$ \\ ${ }^{1}$ Okayama Prefectural University \\ ${ }^{2}$ Chugoku Rubber Industry Co. Ltd. \\ Japan
}

\section{Introduction}

A prediction method for rubber curing process has historically received considerable attention in manufacturing process for rubber article with relatively large size. In recent years, there exists increasing demand for simulation driven design which will cut down the cost and time required for product development. In case of the rubber with relatively large dimensions, low thermal conductivity of the rubber leads to non-uniform distributions of the temperature history, which results in non-uniform cure state in the rubber. Since rubber curing process is an exothermic reaction, both heat conduction equation and expressions for the curing kinetics must be solved simultaneously.

\subsection{Summary of previous works}

In general, three steps exist for rubber curing process, namely, induction, crosslinking and post-crosslinking (e.g. Ghoreishy 2009). In many previous works, interests are attracted in the former two, and a sampling of the relevant literature shows two types of the prediction methods for the curing kinetics.

First type of the method consists of a set of rate equations describing chemical kinetics. Rubber curing includes many complicated chemical reactions that might delay the modelling for practical use. Coran (1964) proposed a simplified model which includes the acceleration, crosslinking and scorch-delay. After the model was proposed, some improvements have been performed (e.g. Ding et al, 1996). Onishi and Fukutani $(2003 a, 2003 b)$ performed experiments on the sulfur curing process of styrene butadiene rubber with nine sets of sulfur/CBS concentrations and peroxide curing process for several kinds of rubbers. Based on their results, they proposed rate equation sets by analyzing the data obtained using the oscillating rheometer operated in the range $403 \mathrm{~K}$ to $483 \mathrm{~K}$ at an interval of $10 \mathrm{~K}$. Likozar and Krajnc (2007) proposed a kinetic model for various blends of natural and polybutadiene rubbers with sulphur curing. Their model includes postcrosslinking chemistry as well as induction and crosslinking chemistries. Abhilash et al. (2010) simulated curing process for a $20 \mathrm{~mm}$ thick rubber slab, assuming one-dimensional heat conduction model. Likazor and Krajnc $(2008,2011)$ studied temperature dependencies of relevant thermophysical properties and simulated curing process for a $50 \mathrm{~mm}$ thick rubber sheet heated below, and good agreements of temperature and degree of cure have been obtained between the predicted and measured values. 
The second type prediction method combines the induction and crosslinking steps in series. The latter step is usually expressed by an equation of a form $\mathrm{d} \varepsilon / \mathrm{d} \tau=\mathrm{f}(\varepsilon, T)$, where $\varepsilon$ is the degree of cure, $\tau$ is the elapsed time and $T$ is the temperature. Ghoreishy (2009) and Rafei et al. (2009) reviewed recent studies on kinetic models and showed a computer simulation technique, in which the equation of the form $d \varepsilon / d \tau=f(\varepsilon, T)$ is adopted. The form was developed by Kamal and Sourour (1973) then improved by many researchers (e.g. Isayev and Deng, 1987) and recently the power law type models are used for non-isothermal, threedimensional design problems (e.g. Ghoreishy and Naderi, 2005).

Temperature field is governed by transient, heat conduction equation with internal heat generation due to the curing reaction. Parameters affecting the temperature history are dimensions, shape and thermophysical properties of rubbers. Also initial and boundary conditions are important factors. Temperature dependencies of relevant thermophysical properties are, for example, discussed in Likozar and Krajnc (2008) and Goyanes et al.(2008). Few studies have been done accounting for the relation between curing characteristics and swelling behaviour (e.g. Ismail and Suzaimah, 2000). Most up-to-date literature may be Marzocca et al. (2010), which describes the relation between the diffusion characteristics of toluene in polybutadiene rubber and the crosslinking characteristics. Effects of sulphur solubility on rubber curing process are not fully clarified (e.g. Guo et al., 2008).

Since the mechanical properties of rubbers strongly depend on the degree of cure, new attempts can be found for making a controlled gradient of the degree of cure in a thick rubber part (e.g. Labban et al., 2007). To challenge the demand, more precise considerations for the curing kinetics and process controls are required.

\subsection{Objective of the present chapter}

As reviewed in the above subsection, many magnificent experimental and theoretical studies have been conducted from various points of view. However, few fundamental studies with relatively large rubber size have been done to develop a computer simulation technique. Nozu et al. (2008), Tsuji et al. (2008) and Baba et al. (2008) have conducted experimental and theoretical studies on the curing process of rubbers with relatibely large size. Rubbers tested were styrene butadiene rubbers with different sulphur concentration, and a blend of styrene butadiene rubber and natural rubber. Present chapter is directed toward developing a prediction method for curing process of rubbers with relatively large size. Features of the chapter can be summarized as follows.

1. Experiments with one-dimensional heat conduction in the rubber were planned to consider the rubber curing process again from the beginning. Thick rubber samples were tested in order to clarify the relation between the slow heat penetration in the rubber and the onset and progress of the curing reaction.

2. The rate equation sets derived by Onishi and Fukutani $(2003 a, 2003 b)$ were adopted for describing the curing kinetics.

3. Progress of the curing reaction in the cooling process was studied.

4. Distributions of the crosslink density in the rubber were determined from the equation developed by Flory and Rehner (1943a, 1943b) using the experimental swelling data.

5. Comparisons of the distributions of the temperature history and the degree of cure between the model calculated values and the measurements were performed. 


\section{Experimental methods}

The most typical curing agent is sulfur, and another type of the agent is peroxide (e.g. Hamed, 2001). In this section, summary of our experimental studies are described. Two types of curing systems were examined. One is the styrene butadiene rubber with sulfur/CBS system (Nozu et al., 2008). The other is the blend of styrene butadiene rubber and natural rubber with peroxide system (Baba et al., 2008).

\subsection{Styrene Butadiene Rubber (SBR)}

Figure 1 illustrates the mold and the positions of the thermocouples for measuring the rubber temperatures (rubber thermocouples). A steel pipe with inner diameter of $74.6 \mathrm{~mm}$ was used as the mold in which rubber sample was packed. On the outer surface of the mold, a spiral semi-circular groove with diameter $3.2 \mathrm{~mm}$ was machined with $9 \mathrm{~mm}$ pitch, and four sheathed-heaters with $3.2 \mathrm{~mm}$ diameter, $\mathrm{a} \sim \mathrm{d}$, were embedded in the groove. On the outer surface of the mold, silicon coating layer was formed and a grasswool insulating material was rolled. The method described here provides one-dimensional radial heat conduction excepting for the upper and lower ends of the rubber.

Four 1-mm-dia type-E sheathed thermocouples, A D, were located in the mold as the wall thermocouples. Four 1-mm-dia Type-K sheathed thermocouples were equipped with the mold to control the heating wall temperatures. The top and bottom surfaces were the composite walls consisting of a Teflon sheet, a wood plate and a steel plate to which an auxiliary heater is embedded.

To measure the radial temperature profile in the rubber, eight type-J thermocouples were located from the central axis to the heating wall at an interval of $5 \mathrm{~mm}$. At the central axis just below $60 \mathrm{~mm}$ from the mid-plane of the rubber, a type-J thermocouple was also located to measure the temperature variation along the axis. All the thermocouples were led out through the mold and connected to a data logger, and all the temperature outputs were subsequently recorded to $0.1 \mathrm{~K}$.

Styrene butadiene rubber (SBR) was used as the polymer. Key ingredients include sulfur as the curing agent, carbon blacks as the reinforced agent. Ingredients of the compounded rubber are listed in Table 1, where sulfur concentrations of $1 \mathrm{wt} \%$ and $5 \mathrm{wt} \%$ were prepared. To locate the rubber thermocouples at the prescribed positions, rubber sheets with 1 and 2 mm thick were rolled up with rubber thermocouples and packed in the mold.

Two curing methods, Method A and Method B, were adopted. Method A is that the heating wall temperature was maintained at $414 \mathrm{~K}$ during the curing process. Method $\mathrm{B}$ is that the first 45 minutes, the wall temperature was maintained at $414 \mathrm{~K}$, then the electrical inputs to the heaters were switched off and the rubber was left in the mold from 0 to 75 minutes at an interval of 15 minutes to observe the progress of curing without wall heating. By adopting the Method B, six kinds of experimental data with different cooling time were obtained. The heater inputs were ac 200 volt at the beginning of the experiment to attain the quick rise of to the prescribed heating wall temperature.

After each experiment was terminated, the rubber sample was brought out quickly from the mold then immersed in ice water, and a thin rubber sheet with $5 \mathrm{~mm}$ thick was sliced just below the rubber thermocouples to perform the swelling test. As shown in Fig.2, eight test pieces at an interval of $5 \mathrm{~mm}$ were cut out from the sliced sheet. Each test piece has dimensions of $3 \mathrm{~mm} \times 3 \mathrm{~mm} \times 5 \mathrm{~mm}$ and swelling test with toluene was conducted. 

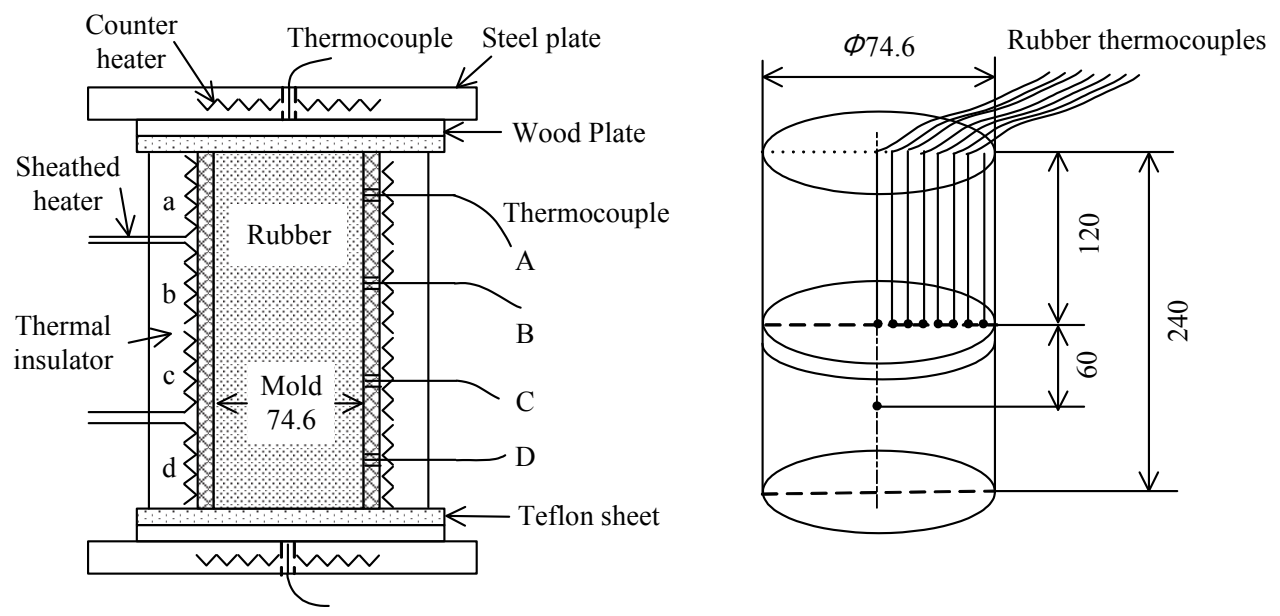

Fig. 1. Experimental mold and positions of rubber thermocouples for SBR

\begin{tabular}{l|c|c}
\hline Ingredients & $\mathrm{wt} \%$ & $\mathrm{wt} \%$ \\
\hline Polymer (SBR) & 53.8 & 51.6 \\
\hline Cure agent (Sulfur) & 1.0 & 5.0 \\
\hline Vulcanization accelerator & 0.9 & 0.9 \\
\hline Reinforcing agent (Carbon black) & 31.9 & 30.6 \\
\hline Softner & 8.0 & 7.6 \\
\hline Activator (1) & 2.6 & 2.5 \\
\hline Activator (2) & 0.5 & 0.5 \\
\hline Antioxidant (1) & 0.5 & 0.5 \\
\hline Antioxidant (2) & 0.3 & 0.3 \\
\hline Antideteriorant & 0.3 & 0.5 \\
\hline
\end{tabular}

Table 1. Ingredients of compounded SBR

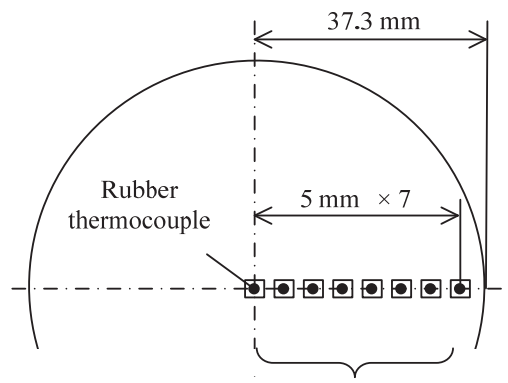

Test pieces for swelling test $(3 \times 3 \times 5 \mathrm{~mm})$

Fig. 2. Cross sectional view at mid-plane of rubber sample 
The crosslink density was evaluated from the equation proposed by Flory and Rehner $(1943 a, 1943 b)$ using the measured results of the swelling test. In the present study, the degree of cure $\varepsilon$ is defined by

$$
\varepsilon=[\mathrm{RX}] /[\mathrm{RX}]_{0}
$$

where $[R X]$ is the crosslink density at an arbitrary condition and $[R X]_{0}$ is that for the fully cured condition obtained from our preliminary experiment.

\subsection{Styrene Butadiene Rubber and Natural Rubber blend (SBR/NR)}

Figure 3 illustrates cross-section of the mold which consists of a rectangular mold with inner dimensions of $100 \mathrm{~mm} \times 100 \mathrm{~mm} \times 30 \mathrm{~mm}$ and upper and lower aluminum-alloy hot plates heated by steam. Rubber sample was packed in the cavity.

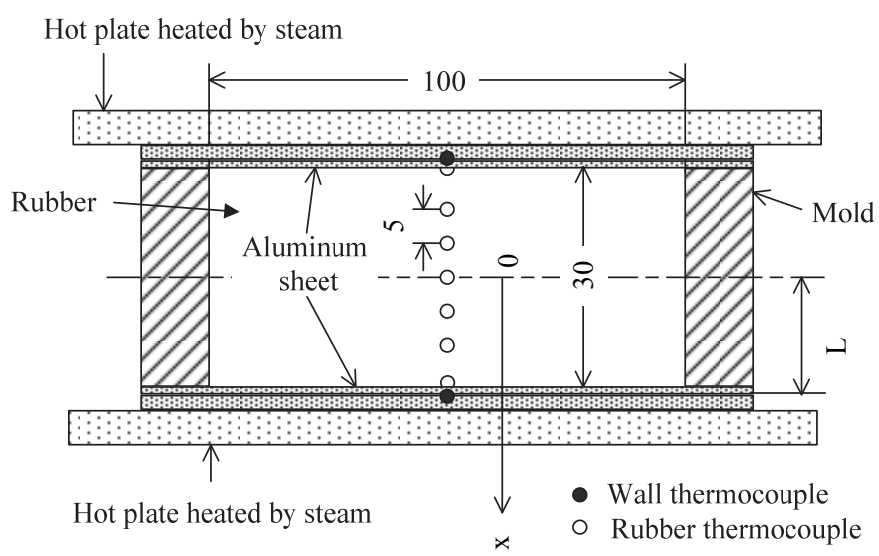

Fig. 3. Experimental mold and hot plates for SBR/NR

Energy transfer in the rubber is predominantly one-dimensional, transient heat conduction from the top and bottom plates to the rubber. To measure the through-the-thickness temperature profile along the central axis in the rubber, type-J thermocouples were located at an interval of $5 \mathrm{~mm}$. Two wall thermocouples were packed between the hotplates and the rubber. All the thermocouples were led out through the mold and connected to the data logger, and the temperature outputs were subsequently recorded to $0.1 \mathrm{~K}$. The blend prepared includes $70 \mathrm{wt} \%$ styrene butadiene rubber (SBR) and $30 \mathrm{wt} \%$ natural rubber (NR). The peroxide was used as the curing agent. Ingredients are listed in Table 2.

To locate the rubber thermocouples at the prescribed positions rubber sheets with $5 \mathrm{~mm}$ thick were superposed appropriately.

Experiments were conducted under the condition of the heating wall temperature $433 \mathrm{~K}$ by changing the heating time in several steps from 50 to 120 minutes in order to study the dependencies of the degree of cure on the heating time. After the heating was terminated, the rubber was led out from the mold then immersed in ice water. The rubber was sliced 3 $\mathrm{mm}$ thick $\times 30 \mathrm{~mm}$ long in the vicinity of the central axis. Test pieces were prepared with dimensions of $3 \mathrm{~mm} \times 3 \mathrm{~mm} \times 3 \mathrm{~mm}$ at $x=-10,-5,0,5$ and $10 \mathrm{~mm}$, where the coordinate $x$ is 
defined in Fig.3. The crosslink density was evaluated from the Flory-Rehner equation using the measured swelling data.

\begin{tabular}{l|c}
\hline Ingredients & $\mathrm{wt} \%$ \\
\hline Polymer (SBR/NR) 70wt\%SBR, 30wt\%NR & 86.2 \\
\hline Cure agent (Peroxide) & 0.4 \\
\hline Reinforcing agent (Silica) & 8.6 \\
\hline Processing aid & 0.3 \\
\hline Activator & 1.7 \\
\hline Antioxidant (1) & 0.9 \\
\hline Antioxidant (2) & 0.9 \\
\hline Coloring agent (1) & 0.2 \\
\hline Coloring agent (2) & 0.8 \\
\hline
\end{tabular}

Table 2. Ingredients of compounded SBR/NR

\section{Numerical prediction}

Rubber curing processes such as press curing in a mold and injection curing are usually operated under unsteady state conditions. In case of the rubber with relatively large dimensions, low thermal conductivity of the rubber leads to non-uniform thermal history, which results to non-uniform degree of cure.

The present section describes theoretical models for predicting the degree of cure for the SBR and SBR/NR systems shown in the previous section. The model consists of solving onedimensional, transient heat conduction equation with internal heat generation due to cureing reaction.

\subsection{Heat conduction}

Heat conduction equation with constant physical properties in cylindrical coordinates is

$$
c \rho \frac{\partial T}{\partial \tau}=\frac{\lambda}{r} \frac{\partial}{\partial r}\left(r \frac{\partial T}{\partial r}\right)+\frac{d Q}{d \tau}
$$

subject to

$$
\begin{gathered}
T=T_{\text {init }} \text { for } \tau=0 \\
T=T_{w}(\tau) \text { for } \tau>0 \text { and } r=r_{M} \\
\partial T / \partial r=0 \text { for } \tau>0 \text { and } r=0
\end{gathered}
$$

where $r$ is the radial coordinate, $\tau$ is the time, $\rho$ is the density, $\mathrm{c}$ is the specific heat, $\lambda$ is the thermal conductivity, $T_{M}(\tau)$ is the heating wall temperature, $T_{\text {init }}$ is the initial temperature in the rubber and $r_{\mathrm{M}}$ is the inner radius of the mold.

Heat conduction equation in rectangular coordinates is

$$
c \rho \frac{\partial T}{\partial \tau}=\lambda \frac{d^{2} T}{d x^{2}}+\frac{d Q}{d \tau}
$$


subject to

$$
\begin{gathered}
T=T_{\text {init }} \text { for } \tau=0 \\
T=T_{\mathrm{w}}(\mathrm{t}) \text { for } \tau>0 \text { and } \mathrm{x}= \pm \mathrm{L}
\end{gathered}
$$

where $x$ is the coordinate defined as shown in Fig. 3 . The second term of the right hand sides of equations (2) and (4), dQ/ $d \tau$, show the effect of internal heat generation expressed as

$$
\mathrm{dQ} / \mathrm{d} \tau=\rho \Delta H \mathrm{~d} \varepsilon / \mathrm{d} \tau
$$

where $\Delta H$ is the heat of curing reaction and $\varepsilon$ is the degree of cure.

\subsection{Curing reaction kinetics}

Prediction methods for the degree of cure $\varepsilon$ in equations (2) and (4) have been derived by Onishi and Fukutani(2003a,2003b) and the models are adopted in this chapter.

\subsubsection{Styrene Butadiene Rubber (SBR)}

Curing process of SBR with sulfur has been analyzed and modeled by Onishi and Fukutani (2003a). A set of reactions is treated as the chain one which includes CBS thermal decomposition.

Simplified reaction model is shown in Fig. 4, where $a$ is the effective accelerator, $N$ is the mercapt of accelerator, $M$ is the polysulfide, $R N$ is the polysulfide of rubber, $R^{*}$ is the active point of rubber, and $R X$ is the crosslink site.

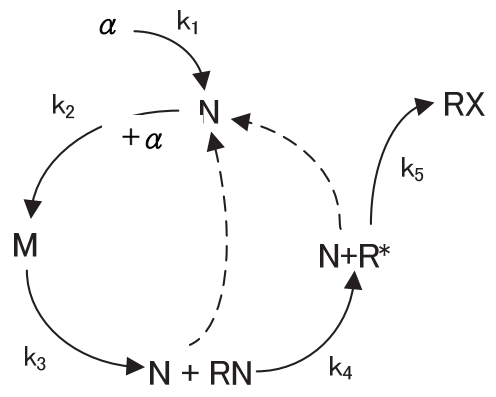

Fig. 4. Simplified curing model for SBR

The model can be expressed by a set of the following five chemical reactions.

$$
\begin{array}{ll}
k_{1} & a \rightarrow N \\
k_{2} & N+a \rightarrow M \\
k_{3} & M \rightarrow R N+N \\
k_{4} & R N \rightarrow R^{*}+N \\
k_{5} & R^{*} \rightarrow R X
\end{array}
$$


which leads the following rate equation set

$$
\begin{aligned}
& \mathrm{d}[a] / \mathrm{d} \tau=-k_{1}[a]-k_{2}[N][a] \\
& \mathrm{d}[N] / \mathrm{d} \tau=k_{1}[a]-k_{2}[N][a]+k_{3}[M]+k_{4}[R N] \\
& \mathrm{d}[M] / \mathrm{d} \tau=k_{2}[N][a]-k_{3}[M] \\
& \mathrm{d}[R N] / \mathrm{d} \tau=k_{3}[\mathrm{M}]-k_{4}[R N] \\
& \mathrm{d}\left[R^{*}\right] / \mathrm{d} \tau=k_{4}[R N]-k_{5}\left[R^{*}\right] \\
& \mathrm{d}[R X] / \mathrm{d} \tau=k_{5}\left[R^{*}\right]
\end{aligned}
$$

where $[a],[N],[M],[R N],\left[R^{*}\right]$ and $[R X]$ are the molar densities of appropriate species. Initial conditions of equation (8) are $[a]=1$ and zero conditions for the rest of species. Rate constants $k_{\mathrm{i}}(\mathrm{i}=1 \sim 5)$ in the set were expressed using the Arrhenius form as

$$
k_{\mathrm{i}}=A_{\mathrm{i}} \exp \left(-E_{\mathrm{i}} / R T\right)
$$

where $A_{i}$ is the frequency factor of reaction $i, E_{\mathrm{i}}$ is the activation energy of reaction $i, R$ is the universal gas constant, $T$ is the absolute temperature. Values of $A_{i}$ and $E_{i}$ are shown in Table 3, where these values were derived from the analysis of the isothermal curing data using the oscillating rheometer in the range $403 \mathrm{~K}$ to $483 \mathrm{~K}$ at an interval of $10 \mathrm{~K}$ (Onishi and Fukutani, 2003a).

\begin{tabular}{|c|c|c|c|c|}
\hline \multirow{2}{*}{$\begin{array}{c}\text { Sulfur } \\
\text { concentration }\end{array}$} & \multicolumn{2}{|c|}{$1 \mathrm{wt} \%$} & \multicolumn{2}{c|}{$5 \mathrm{wt} \%$} \\
\hline & $A_{i}(1 / \mathrm{s})$ & $E_{i} / \mathrm{R}(\mathrm{K})$ & $A_{i}(1 / \mathrm{s})$ & $E_{i} / \mathrm{R}(\mathrm{K})$ \\
\hline$k_{1}$ & $1.034 \times 10^{7}$ & $1.166 \times 10^{4}$ & $1.387 \times 10^{-1}$ & 3.827 \\
\hline$k_{2}$ & $3.159 \times 10^{13}$ & $1.466 \times 10^{4}$ & $5.492 \times 10^{8}$ & 9.973 \\
\hline$k_{3}$ & $2.182 \times 10^{7}$ & $8.401 \times 10^{3}$ & $1.880 \times 10^{9}$ & 9.965 \\
\hline$k_{4}$ & $1.089 \times 10^{7}$ & $8.438 \times 10^{3}$ & $1.160 \times 10^{9}$ & 9.863 \\
\hline$k_{5}$ & $1.523 \times 10^{9}$ & $1.119 \times 10^{4}$ & $1.281 \times 10^{9}$ & $1.135 \times 10$ \\
\hline
\end{tabular}

Table 3. Frequency factor and activation energy for SBR

\subsubsection{Styrene butadiene rubber and natural rubber blend (SBR/NR)}

Peroxide curing process for rubbers has been analyzed and modeled by Onishi and Fukutani (2003b). Simplified reaction model is shown in Fig. 5, where $R$ is possible crosslink site of polymer, $R^{*}$ is active cure site, $P R$ the polymer radical, $R X^{*}$ is the polymer radical with crosslinks and $\mathrm{RX}$ is the crosslink site. 


\begin{tabular}{|c|c|c|}
\hline & $A_{i}(1 / \mathrm{s})$ & $E_{i} / R(\mathrm{~K})$ \\
\hline$k_{1}$ & $1.243 \times 10^{8}$ & $1.095 \times 10^{4}$ \\
\hline$k_{2}$ & $1.007 \times 10^{15}$ & $1.826 \times 10^{4}$ \\
\hline$k_{3}$ & $9.004 \times 10^{2}$ & $6.768 \times 10^{3}$ \\
\hline$k_{4}$ & $2.004 \times 10^{6}$ & $8.860 \times 10^{3}$ \\
\hline$k_{5}$ & $1.000 \times 10^{-6}$ & $-3.171 \times 10^{3}$ \\
\hline
\end{tabular}

Table 4. Frequency factor and activation energy for SBR/NR

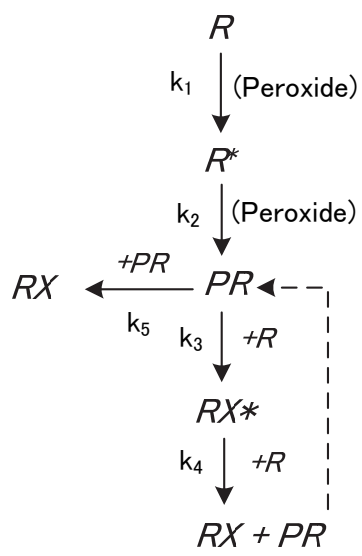

Fig. 5. Simplified curing model for SBR/NR

The model can be expressed by a set of the following five chemical reactions.

$$
\begin{array}{ll}
\mathrm{k}_{1} & \mathrm{R} \rightarrow \mathrm{R}^{*} \\
\mathrm{k}_{2} & \mathrm{R}^{*} \rightarrow \mathrm{PR} \\
\mathrm{k}_{3} & \mathrm{PR}+\mathrm{R} \rightarrow \mathrm{RX}^{*} \\
\mathrm{k}_{4} & \mathrm{RX}^{*}+\mathrm{R} \rightarrow \mathrm{RX}+\mathrm{PR} \\
\mathrm{k}_{5} & \mathrm{PR}+\mathrm{R}^{*} \rightarrow \mathrm{RX}
\end{array}
$$

which leads the following rate equation set

$$
\begin{aligned}
& \mathrm{d}[R] / \mathrm{d} \tau=-k_{1}[R]-k_{3}[P R][R]-k_{4}\left[R X^{*}\right][R] \\
& \mathrm{d}\left[R^{*}\right] / \mathrm{d} \tau=k_{1}[R]-k_{2}\left[R^{*}\right] \\
& \mathrm{d}[P R] / \mathrm{d} \tau=k_{2}\left[R^{*}\right]-k_{3}[P R][R]+k_{4}\left[R X^{*}\right][R]-2 k_{5}[P R]^{2} \\
& \mathrm{~d}\left[R X^{*}\right] / \mathrm{d} \tau=k_{3}[P R][R]-k_{4}\left[R X^{*}\right][R] \\
& \mathrm{d}[R X] / \mathrm{d} \tau=k_{4}\left[R X^{*}\right][R]+k_{5}[P R]^{2}
\end{aligned}
$$


where $[R],\left[R^{*}\right],[P R],\left[R X^{*}\right]$ and $[R X]$ are the molar densities of appropriate species. Initial conditions of equation $(11)$ are $[R]=2$ and zero conditions for the rest of species.

Rate constants $k_{\mathrm{i}}(\mathrm{i}=1 \sim 5)$ are listed in Table 4, where the values were obtained from the similar method conducted by Onishi and Fukutani (2003b).

\subsection{Usage of the equations}

For the SBR with sulfur curing system described in the previous section, we need to solve heat conduction equation (2) together with rate equation set (8) to obtain cure state distributions. Initial and boundary conditions for the temperatures were given by equation (3). Initial concentration conditions are described below equation set (8). Similar method can be adopted for estimating the SBR/NR system.

\begin{tabular}{|c|c|c|c|}
\hline & \multicolumn{2}{|c|}{ SBR } & \multirow{2}{*}{ SBR/NR } \\
\hline & Sulfur $1 \mathrm{wt} \%$ & Sulfur 5wt\% & \\
\hline Density $\rho\left(\mathrm{kg} / \mathrm{m}^{3}\right)$ & \multicolumn{2}{|c|}{$1.165 \times 10^{3}$} & $1.024 \times 10^{3}$ \\
\hline Thermal conductivity $1(\mathrm{~W} / \mathrm{mK})$ & \multicolumn{2}{|c|}{0.33} & 0.20 \\
\hline Specific heat capacity $c(\mathrm{~J} / \mathrm{kgK})$ & \multicolumn{2}{|c|}{$1.84 \times 10^{3}$} & $1.95 \times 10^{3}$ \\
\hline Heat of reaction $\Delta H(\mathrm{~J} / \mathrm{kg})$ & $1.23 \times 10^{4}$ & $3.99 \times 10^{4}$ & $2.78 \times 10^{4}$ \\
\hline
\end{tabular}

Table 5. Physical properties used for prediction

The density $\rho$ was determind using the mixing-rule. The thermal conductivity $\lambda$ was measured using the cured rubber at 293K. DSC measurements of the specific heat capacity $c$ and that of the heat of curing reaction $\Delta H$ for the rubber compounds were performed in the range $293 \mathrm{~K}$ to $453 \mathrm{~K}$. The theromophysical properties used for the prediction are tabulated in Table 5. For the case of SBR with $5 \mathrm{wt} \%$ sulfur, a small correction of the specific heat capacity was made in the range $385.9 \mathrm{~K}$ to $392.9 \mathrm{~K}$ to account for the effect of the fusion heat of crystallized sulfer. The solubility of sulfur in the SBR was assumed to be $0.8 \mathrm{wt} \%$ fom the literature (Synthetic Rubber Divison of JSR, 1989). Heat conduction equations (2) and (4) were respectively reduced to systems of simultaneous algebraic equations by a controlvolume-based, finite difference procedure. Number of control volumes were 37 for SBR with $37.3 \mathrm{~mm}$ radius and 30 for SBR/NR with $30 \mathrm{~mm}$ thick. Time step of $0.5 \mathrm{sec}$ was chosen after some trails.

\section{Comparison with experimental data}

\subsection{Styrene Butadiene Rubber (SBR)}

Figure 6 shows the temperature profile for the cured rubber with Method A, where solid and dashed lines respectively show the numerical results and the measured heating wall temperature. Symbols present measured rubber temperatures. In the figure for the measured temperatures, typical one-dimensional transient temperature field can be observed and it takes about 180 minutes to reach $T_{\mathrm{R}}$ to the final temperature $T_{\mathrm{w}}$. Comparisons of the measured and predicted temperatures show good agreements between them. Also, the measured temperature difference along the axis between the positions at mid-cross section and that at $60 \mathrm{~mm}$ downward was less than $0.5 \mathrm{~K}$. Since the difference is considerably smaller as compared to the radial one, one-dimensional transient heat conduction field is well established in the present experimental mold. 


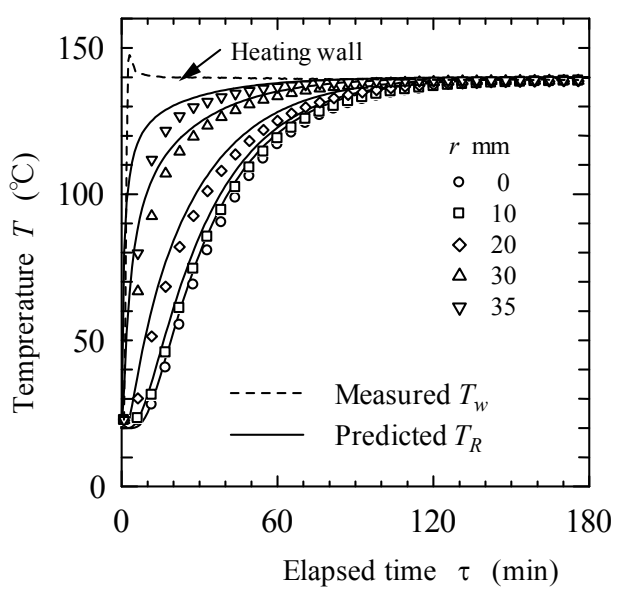

Fig. 6. Temperature profile for cured SBR, Method A

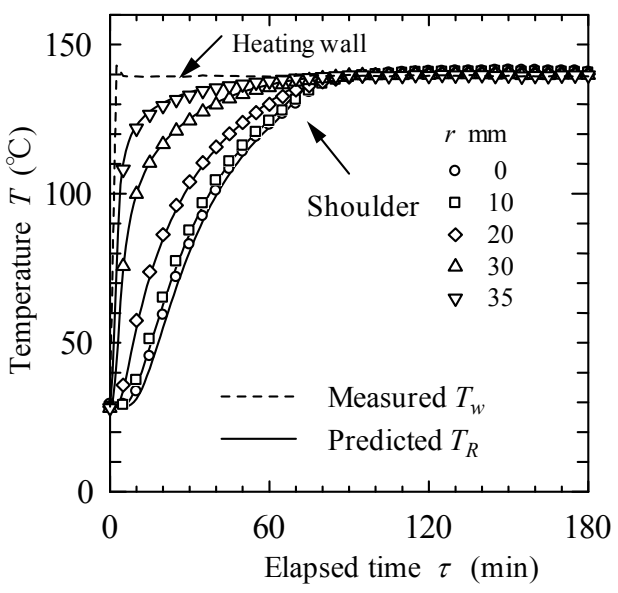

Fig. 7. Temperature profile for SBR with $1 \mathrm{wt} \%$ sulfur, Method A

Figure 7 is the result of the compounded rubber with Method A. The temperature rise is faster for the compounded rubber than for the cured one, and a uniform temperature field is observed at about $\tau=95$ minutes. The former may be caused by the internal heat generation due to curing reaction. The numerical results well follow the measured temperature history.

Figure 8 shows the numerical results of the internal heat generation rate $d Q / d \tau$ and the degree of cure $\varepsilon$ corresponding to the condition of Fig.7. The $\mathrm{dQ} / \mathrm{d} \tau$ at each radial position $r$ 
shows a sharp increase and takes a maximum then decreases moderately. It can also be seen that the onset of the heat generation takes place, for example, at $\tau=15$ minutes for $r=35$ $\mathrm{mm}$, and at $\tau=65$ minutes for $r=0 \mathrm{~mm}$. This means that the induction time is shorter for nearer the heating wall due to slow heat penetration. Another point to note here is that the symmetry condition at $r=0$, equation (3c), leads to the rapid increase of $T_{\mathrm{R}}$ near $r=0$ after $\tau$ $=60$ minutes is reached as shown in Fig.7. The degree of cure $\varepsilon$ increases rapidly just after the onset of curing, then approaches gradually to 1 as shown in the lower part of Fig.8.

Figure 9 shows the profiles of rubber temperature and that of degree of cure, both are model calculated results. An overall comparison of the Figs. 9(a) and 9(b) indicates that the progress of the curing is much slower than the heat penetration. The phenomenon is pronounced in the central region of the rubber. Temperature profiles at $\tau=90$ and 105 minutes were almost unchanged, thus the two profiles can not be distinguished in the figure.

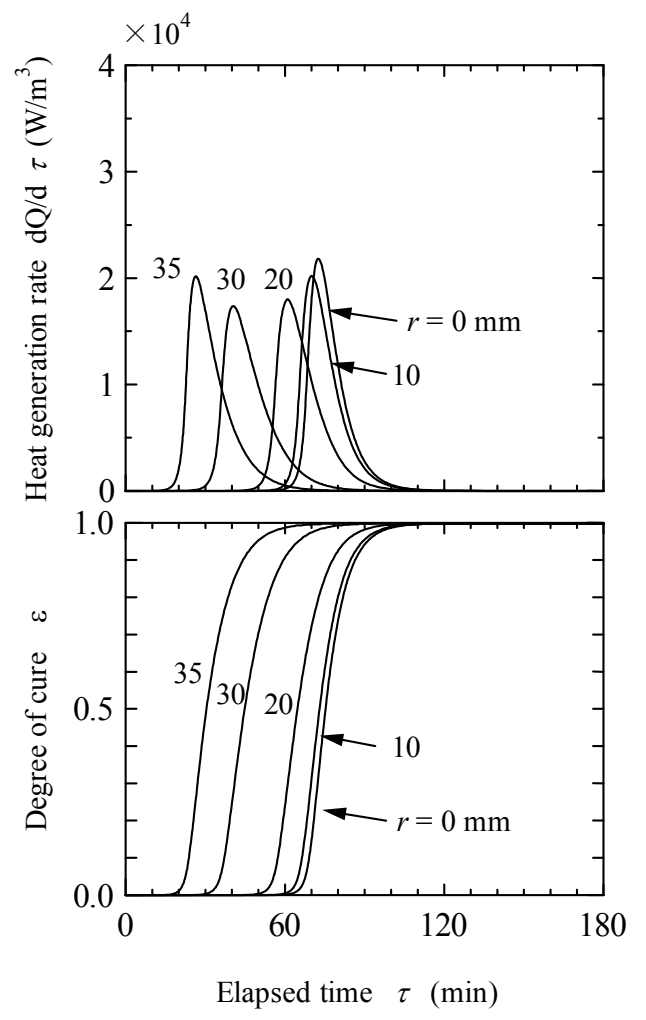

Fig. 8. Heat generation rate $\mathrm{dQ} / \mathrm{d} \tau$ and degree of cure $\varepsilon$ for $\mathrm{SBR}$ with $1 \mathrm{wt} \%$ sulphur, Method A, corresponding to Fig.7 


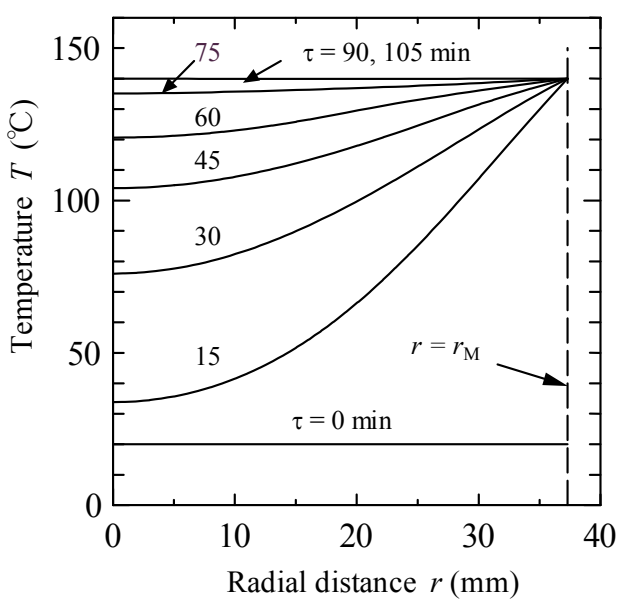

(a) Rubber temperature

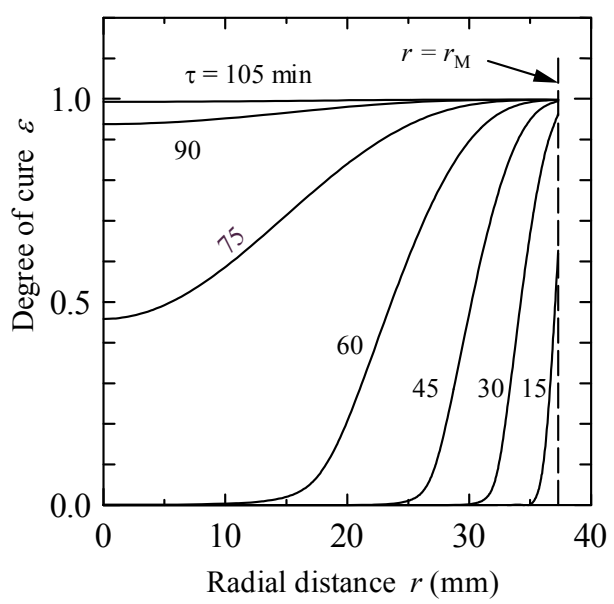

(b) Degree of cure

Fig. 9. Profiles of rubber temperature and degree of cure, SBR with $1 w t \%$ sulphur, Method A, corresponding to Figs.7 and 8

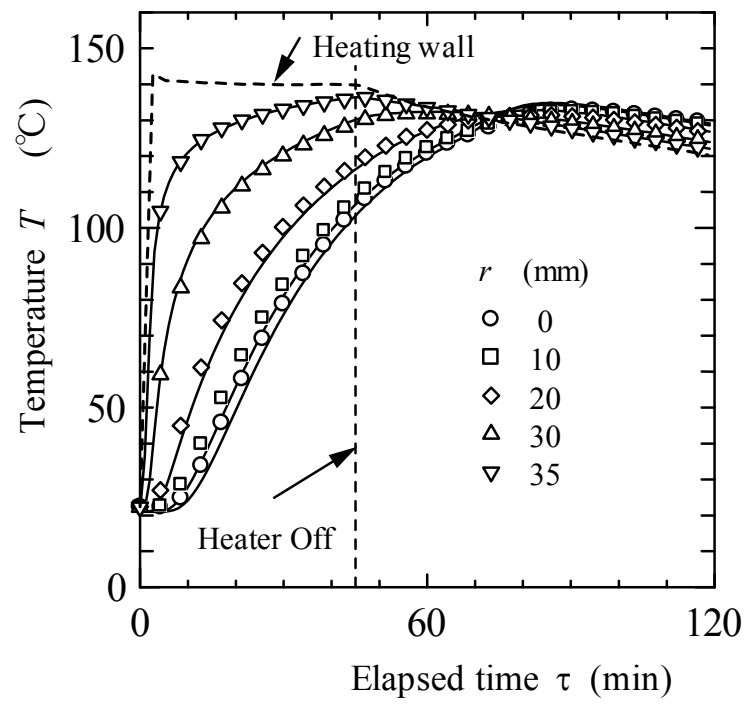

Fig. 10. Profile of rubber temperature for SBR with $1 \mathrm{wt} \%$ sulfur, Method B 
Figures 10 and 11 show the results of the SBR with $1 \mathrm{wt} \%$ sulfur with Method B. In Fig.10 for after $\tau=45$ minutes, $T_{\mathrm{R}}$ at $r=35 \mathrm{~mm}$ decreases monotonically, while that at $r=0 \mathrm{~mm}$ increases and takes maximum at $\tau=90$ minutes, then decreases. After $\tau=75$ minutes, negative temperature gradient to the heating wall can be observed in the rubber. This implies that the outward heat flow to the heating wall exists in the rubber.

In Fig.11 at $\tau=45$ minutes, the reaction only proceeds in the region $r>30 \mathrm{~mm}$, and after $\tau=$ 45 minutes, the reaction proceeds without wall heating. Especially at $r=0 \mathrm{~mm}$, degree of cure $\varepsilon$ increases after $\tau=75$ minutes, where the negative temperature gradient to the heating wall is established as shown in Fig.10. The predicted $\varepsilon$ well follow the measurements after $\tau$ $=45$ minutes. These results indicate that the curing reaction proceeds without wall heating after receiving a certain amount of heat.

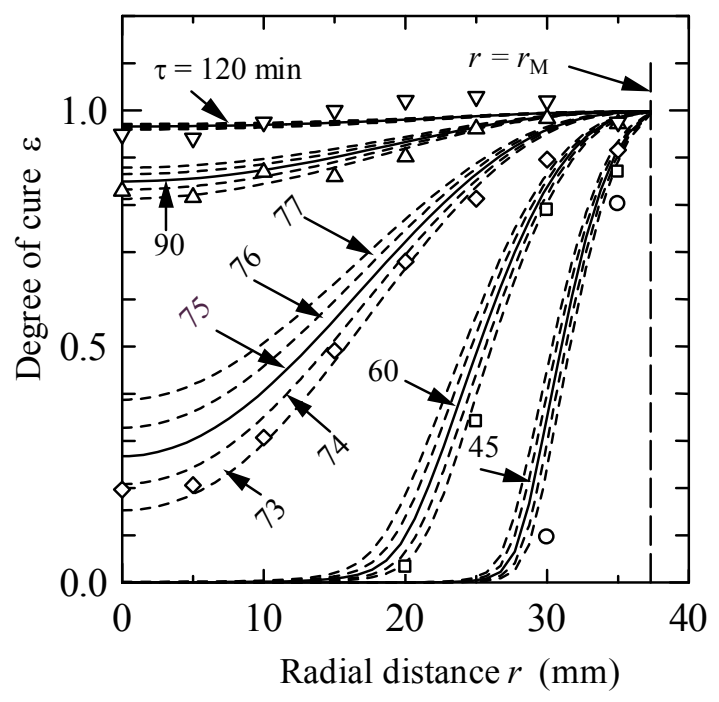

Fig. 11. Profile of degree of cure for SBR with $1 \mathrm{wt} \%$ sulfur, Method B, corresponding to Fig.10

The results in Fig. 10 and 11 reveal that the cooling process plays an important role in the curing process, and wall heating time may be reduced by making a precise modelling for the curing process. Also good agreements of $T_{R}$ and $\varepsilon$ between the predictions and the measurements conclude that the present prediction method is applicable for practical use. Figure 12 plots the numerical results of the internal heat generation rate $d Q / d \tau$ and the degree of cure $\varepsilon$ corresponding to the condition of Fig.10. Comparison of $d Q / d \tau$ between Fig. 8 for Method A and Fig.12 for Method B shows that the effects of wall heating after $\tau=45$ minutes is only a little, namely, the onset of the curing for Method B is a little slower than that for Method A. It takes 91 and 100 minutes for Method A and for Method B respectively to arrive at the condition of $\varepsilon=0.95$ at $r=0 \mathrm{~mm}$. 


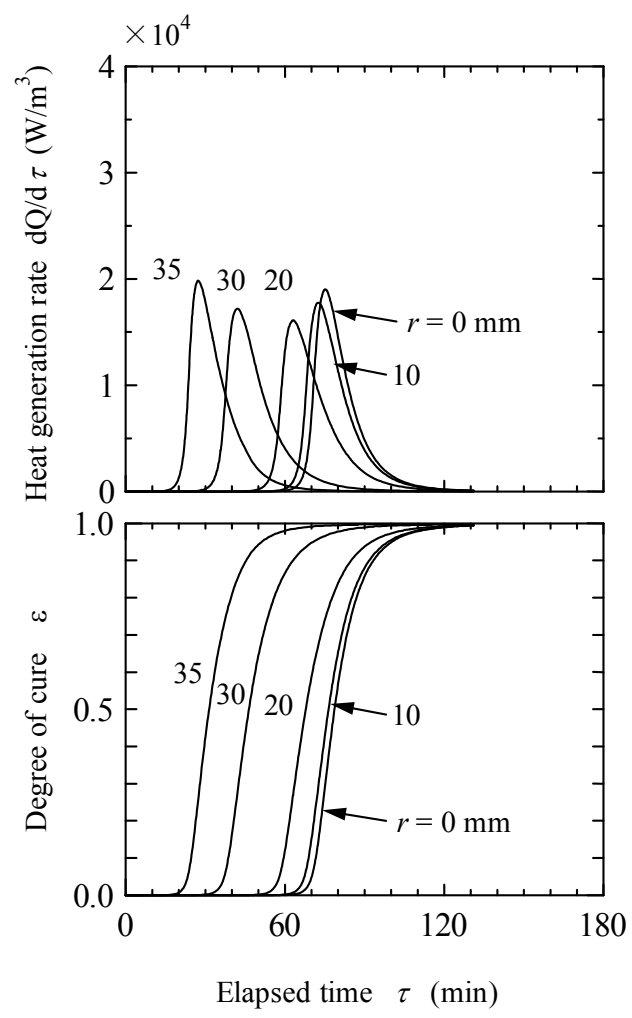

Fig. 12. Heat generation rate $d Q / d \tau$ and degree of cure $\varepsilon$ for SBR with $1 \mathrm{wt} \%$ sulphur, Method B, corresponding to Figs. 10 and 11

Figures 13 and 14 show the results of SRB with $5 \mathrm{wt} \%$ sulfur. Model calculated temperatures in Fig.13 well follow the measurements before $\tau=80$ minutes. An overall inspection of $\mathrm{dQ} / \mathrm{d} \tau$ in Figs. 8 and 14 shows that the induction time for $5 \mathrm{wt} \%$ is shorter than for $1 \mathrm{wt} \%$, whereas the $\mathrm{d} \varepsilon / \mathrm{d} \tau$ for $5 \mathrm{wt} \%$ is smaller than for $1 \mathrm{wt} \%$. Also the amount of heat generation rate for each $r$ is more remarkable for $5 \mathrm{wt} \%$ than for $1 \mathrm{wt} \%$. It takes 89 minutes to arrive at the condition of $\varepsilon=0.95$ at $r=0 \mathrm{~mm}$.

Again in Fig.13, in the region after $\tau=80$ minutes, the rubber temperature less than $r=20$ $\mathrm{mm}$ increases and takes maximum of $429 \mathrm{~K}$ then gradually decrease. The model can not predict the experimental results. It is not possible to make conclusive comments, but the experimental results may be caused by the crosslink decomposition reaction, complex behaviour of free sulfur, etc. not taken into consideration in the present prediction model. Effects of sulphur on the curing kinetics, especially on the post-crosslinking chemistry have not been well solved. For reference, recently Miliani,G. and Miliani,F (2011) reviewed relevant literature and proposed a macroscopic analysis. 


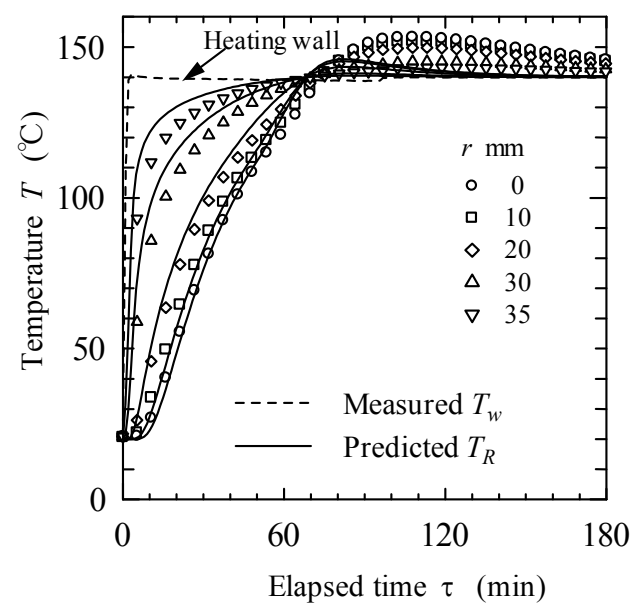

Fig. 13. Temperature profile for SBR with $5 \mathrm{wt} \%$ sulphur

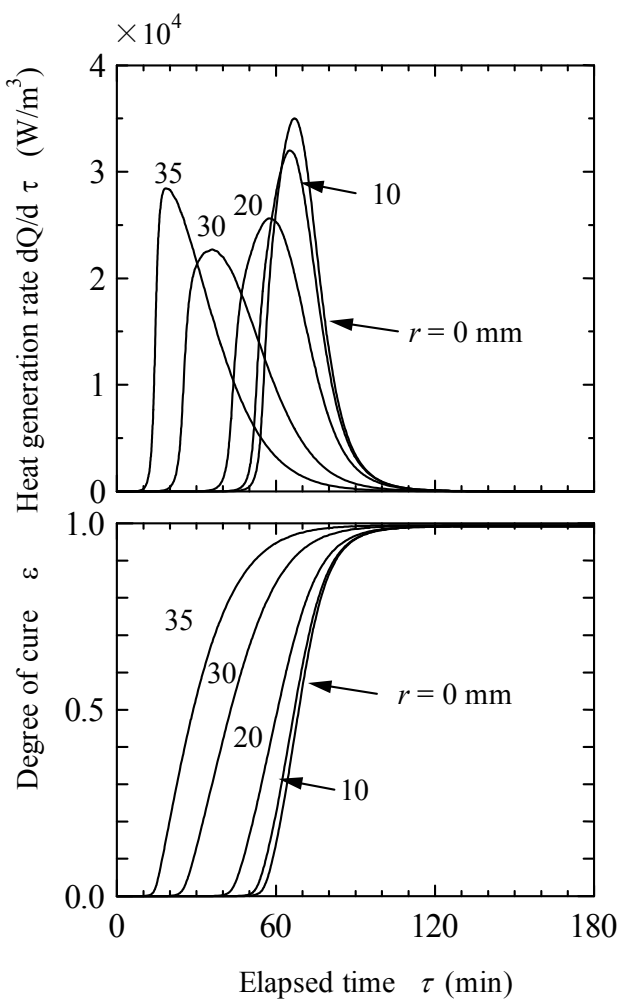

Fig. 14. Heat generation rate $\mathrm{dQ} / \mathrm{d} \tau$ and degree of cure $\varepsilon$ for SBR with $5 \mathrm{wt} \%$ sulphur, corresponding to Fig.13 


\subsection{Styrene Butadiene Rubber and Natural Rubber blend (SBR/NR)}

Figures 15 and 16 show the SBR/NR results. As shown in the figures, the experimental results of rubber temperature and degree of cure almost follow the predictions.

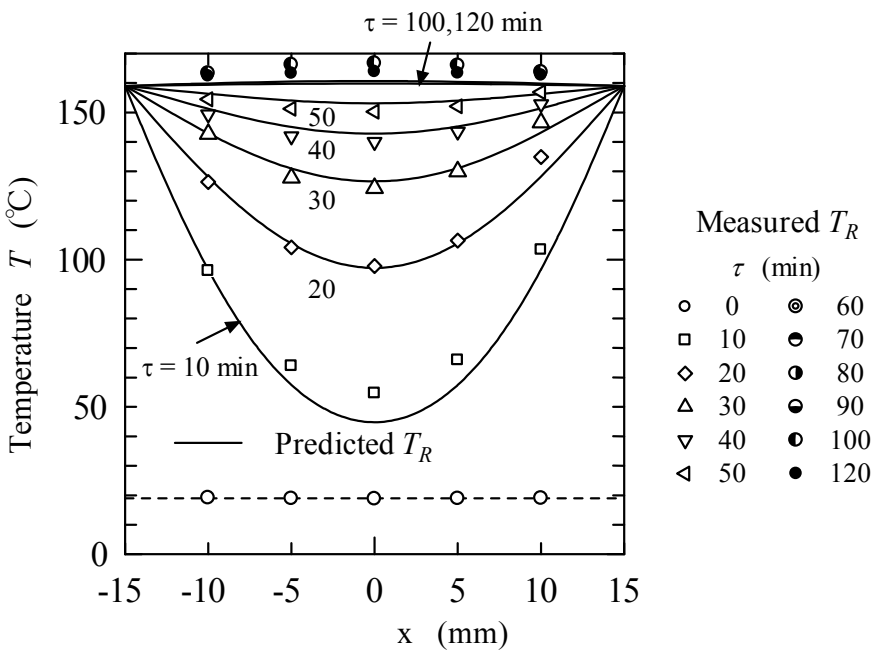

Fig. 15. Cross-sectional view of temperature history for SBR/NR

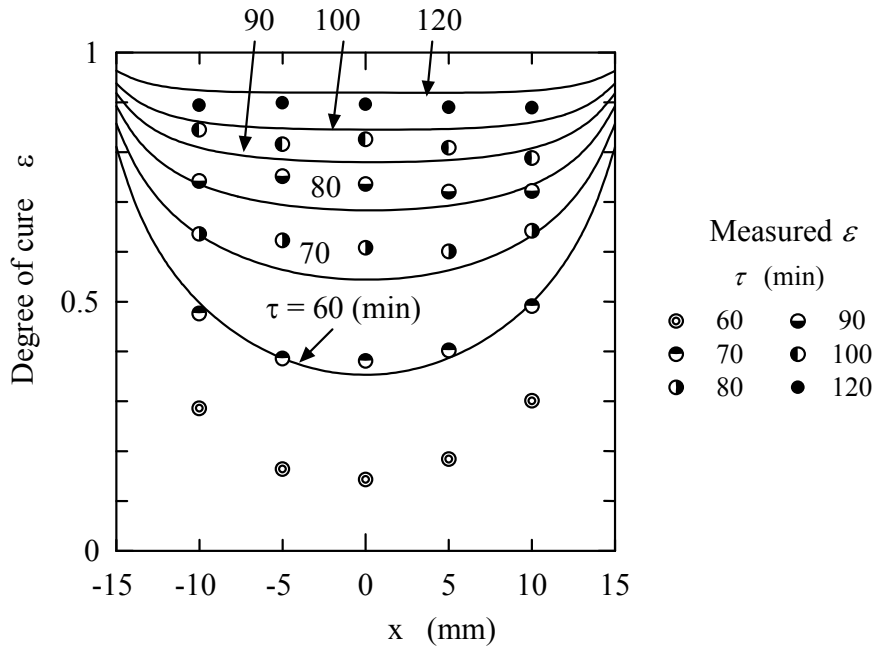

Fig. 16. Cross-sectional view of degree of cure for SBR/NR, corresponding to Fig.15

It is clear that the temperature at smaller $\mathrm{x}$ after $\tau=60$ minutes is higher than the heating wall value. This is due to the effect of internal heat generation.

Figure 17 plots the model calculated values of $\mathrm{dQ} / \mathrm{d} \tau$ and $\varepsilon$, where values at the heating wall $(x=15 \mathrm{~mm})$ are also shown for reference. A quick comparison of Fig. 8 for SBR and Fig.17 for SBR/NR apparently indicates that the gradient of $d \varepsilon / d \tau$ for SBR is larger than that for 
SBR/NR. This means that more precious expression for curing kinetics may be required for making a controlled gradient of the degree of cure in a thick rubber part, because thermal history influences the curing process.

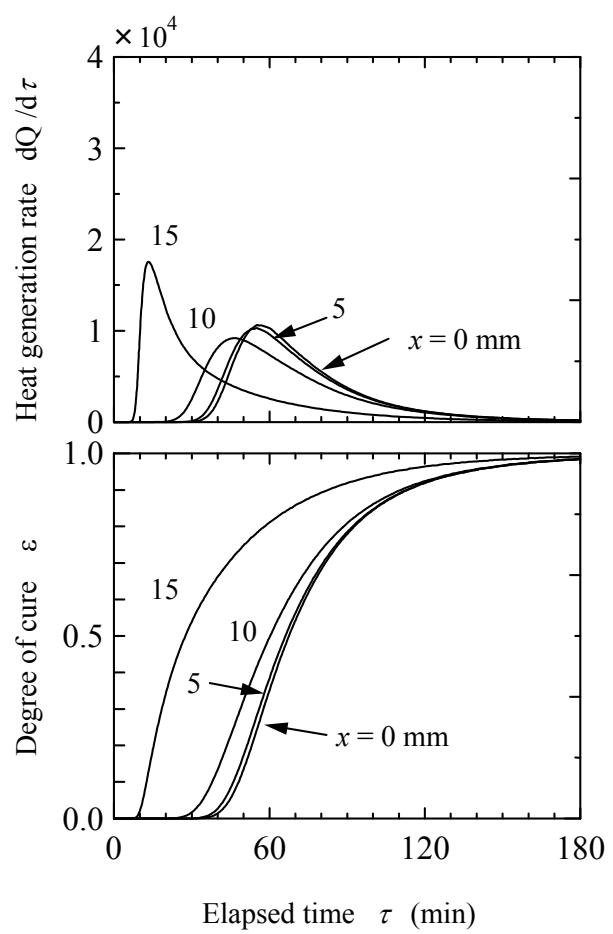

Fig. 17. Heat generation rate $\mathrm{dQ} / \mathrm{d} \tau$ and degree of cure $\varepsilon$ for SBR/NR, corresponding to Figs. 15 and 16

\section{Concluding remarks}

A Prediction method for rubber curing process has been proposed. The method is derived from our experimental and numerical studies on the styrene butadiene rubber with sulphur curing and the blend of styrene butadiene rubber and natural rubber with peroxide curing systems. Following concluding remarks can be derived.

1. Rate equation sets (8) and (11), both obtained from isothermal oscillating rheometer studies, are applicable for simulation driven design of rubber article with relatively large size. The former set is applicable to SBR with sulphur/CBR curing and the latter for rubbers with peroxide curing.

2. Rafei et al. (2009) has pointed out that no experimental verification on the accuracy of the predicted degree of cure comparing with directly measured data. It is important to solve this problem as quickly as possible. When the problem is solved, it can determine whether or not to take into account the effects of temperature dependencies of thermophysical properties. 
3. Curing reaction under the temperature decreasing stage can also be evaluated by the present prediction method.

4. Extension of the present prediction methods to realistic three-dimensional problems may be relatively easy, since we have various experiences in the fields of numerical simulation and manufacturing technology.

\section{References}

Abhilash, P.M. et al., (2010). Simulation of Curing of a Slab of Rubber, Materials Science and Engineering B, Vol.168, pp.237-241, ISSN 0921-5107

Baba T. et al., (2008). A Prediction Method of SBR/NR Cure Process, Preprint of the Japan Society of Mechanical Engineers, Chugoku-Shikoku Branch, No.085-1, pp.217-218, Hiroshima, March, 2009

Coran, A.Y. (1964). Vulcanization. Part VI. A Model and Treatment for Scorch Delay Kinetics, Rubber Chemistry and Technology, Vol.37, pp. 689-697, ISSN=0035-9475

Ding, R. et al., (1996). A Study of the Vulcanization Kinetics of an Accelerated-Sulfur SBR Compound, Rubber Chemistry and Technology, Vol.69, pp. 81-91, ISSN= 0035-9475

Flory, P.J and Rehner,J (1943a). Statistical Mechanics of Cross-Linked Polymer Networks I. Rubberlike Elasticity, Journal of Chemical Physics, Vol.11, pp.512- ,ISSN= 0021-9606

Flory, P.J and Rehner,J (1943b). Statistical Mechanics of Cross-Linked Polymer Networks II. Swelling, Journal of Chemical Physics, Vol.11, pp.521- ,ISSN=0021-9606

Guo,R., et al., (2008). Solubility Study of Curatives in Various Rubbers, European Polymer Journal, Vol.44, pp.3890-3893, ISSN=0014-3057

Ghoreishy, M.H.R. and Naderi, G. (2005). Three-dimensional Finite Element Modeling of Rubber Curing Process, Journal of Elastomers and Plastics, Vol.37, pp.37-53, ISSN 0095-2443

Ghoreishy M.H.R. (2009). Numerical Simulation of the Curing Process of Rubber Articles, In : Computational Materials, W. U. Oster (Ed.) , pp.445-478, Nova Science Publishers, Inc., ISBN= 9781604568967, New York

Goyanes, S. et al., (2008). Thermal Properties in Cured Natural Rubber/Styrene Butadiene Rubber Blends, European Polymer Journal, Vol.44, pp.1525-1534, ISSN= 0014-3057

Hamed,G.R. (2001). Engineering with Rubber; How to Design Rubber Components (2nd edition), Hanser Publishers, ISBN=1-56990-299-2, Munich

Ismail,H. and Suzaimah,S. (2000). Styrene-Butadiene Rubber/Epoxidized Natural Rubber Blends: Dynamic Properties, Curing Characteristics and Swelling Studies, Polymer Testing, Vol.19, pp.879-888, ISSN=01420418

Isayev, A.I. and Deng, J.S. (1987). Nonisothermal Vulcanization of Rubber Compounds, Rubber Chemistry and Technology, Vol.61, pp.340-361, ISSN 0035-9475

Kamal, M.R. and Sourour,S., (1973). Kinetics and Thermal Characterization of Thermoset Cure, Polymer Engineering and Science, Vol.13, pp.59-64, ISSN=0032-3888

Labban A. EI. et al., (2007). Numerical Natural Rubber Curing Simulation, Obtaining a Controlled Gradient of the State of Cure in a Thick-section Part, In:10th ESAFORM Conference on Material Forming (AIP Conference Proceedings), pp.921-926, ISBN= 9780735404144

Likozar,B. and Krajnc,M. (2007). Kinetic and Heat Transfer Modeling of Rubber Blends' Sulfur Vulcanization with N-t-Butylbenzothiazole-sulfenamide and N,N-Di-t- 
butylbenzothiazole-sulfenamide, Journal of Applied Polymer Science, Vol.103, pp.293307. ISSN=0021-8995

Likozar, B. and Krajnc, M. (2008). A Study of Heat Transfer during Modeling of Elastomers, Chemical Engineering Science, Vol.63, pp.3181-3192, ISSN 0009-2509

Likozar,B. and Krajnc,M. (2011). Cross-Linking of Polymers: Kinetics and Transport Phenomena, Industrial \& Engineering Chemistry Research, Vol.50, pp.1558-1570. ISSN $=0888-5885$

Marzocca,A.J. et al., (2010). Cure Kinetics and Swelling Behaviour in Polybutadiene Rubber, Polymer Testing, Vol.29, pp.477-482, ISSN= 0142-9418

Milani,G and Milani,F. (2011). A Three-Function Numerical Model for the Prediction of Vulcanization-Reversion of Rubber During Sulfur Curing, Journal of Applied Polymer Science, Vol.119, pp.419-437, ISSN= 0021-8995

Nozu,Sh. et al., (2008). Study of Cure Process of Thick Solid Rubber, Journal of Materials Processing Technology, Vol.201, pp.720-724 , ISSN=0924-0136

Onishi,K and Fukutani,S. (2003a). Analyses of Curing Process of Rubbers Using Oscillating Rheometer, Part 1. Kinetic Study of Curing Process of Rubbers with Sulfur/CBS, Journal of the Society of Rubber Industry, Japan, Vol.76, pp.3-8, ISSN=0029-022X

Onishi,K and Fukutani,S. (2003b). Analysis of Curing Process of Rubbers Using Oscillating Rheometer, Part 2. Kinetic Study of Peroxide Curing Process of Rubbers, Journal of the Society of Rubber Industry, Japan, Vol.76, pp.160-166, ISSN=0029-022X

Rafei, $M$ et al., (2009). Development of an Advanced Computer Simulation Technique for the Modeling of Rubber Curing Process. Computational Materials Science, Vol.47, pp. 539-547, ISSN 1729-8806

Synthetic Rubber Division of JSR Corporation, (1989). JSR HANDBOOK, JSR Corporation, Tokyo

Tsuji, H. et al., (2008). A Prediction Method for Curing Process of Styrene-butadien Rubber, Transactions of the Japan Society of Mechanical Engineers, Ser.B, Vol.74, pp.177-182, ISSN=0387-5016 


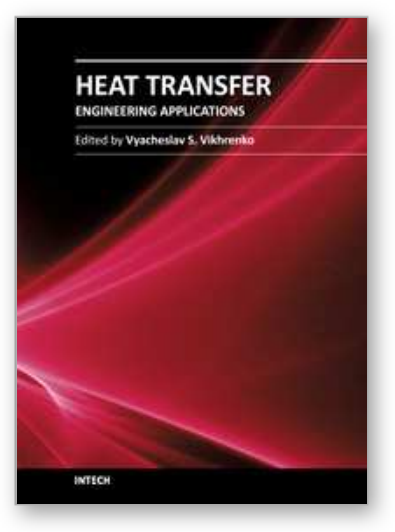

\author{
Heat Transfer - Engineering Applications \\ Edited by Prof. Vyacheslav Vikhrenko
}

ISBN 978-953-307-361-3

Hard cover, 400 pages

Publisher InTech

Published online 22, December, 2011

Published in print edition December, 2011

Heat transfer is involved in numerous industrial technologies. This interdisciplinary book comprises 16 chapters dealing with combined action of heat transfer and concomitant processes. Five chapters of its first section discuss heat effects due to laser, ion and plasma-solid interaction. In eight chapters of the second section engineering applications of heat conduction equations to the curing reaction kinetics in manufacturing process, their combination with mass transport or ohmic and dielectric losses, heat conduction in metallic porous media and power cables are considered. Analysis of the safety of mine hoist under influence of heat produced by mechanical friction, heat transfer in boilers and internal combustion engine chambers, management for ultrahigh strength steel manufacturing are described in this section as well. Three chapters of the last third section are devoted to air cooling of electronic devices.

\title{
How to reference
}

In order to correctly reference this scholarly work, feel free to copy and paste the following:

Shigeru Nozu, Hiroaki Tsuji and Kenji Onishi (2011). A Prediction Model for Rubber Curing Process, Heat Transfer - Engineering Applications, Prof. Vyacheslav Vikhrenko (Ed.), ISBN: 978-953-307-361-3, InTech, Available from: http://www.intechopen.com/books/heat-transfer-engineering-applications/a-prediction-modelfor-rubber-curing-process

\section{INTECH}

open science | open minds

\author{
InTech Europe \\ University Campus STeP Ri \\ Slavka Krautzeka 83/A \\ 51000 Rijeka, Croatia \\ Phone: +385 (51) 770447 \\ Fax: +385 (51) 686166 \\ www.intechopen.com
}

\author{
InTech China \\ Unit 405, Office Block, Hotel Equatorial Shanghai \\ No.65, Yan An Road (West), Shanghai, 200040, China \\ 中国上海市延安西路65号上海国际贵都大饭店办公楼405单元 \\ Phone: +86-21-62489820 \\ Fax: +86-21-62489821
}


(C) 2011 The Author(s). Licensee IntechOpen. This is an open access article distributed under the terms of the Creative Commons Attribution 3.0 License, which permits unrestricted use, distribution, and reproduction in any medium, provided the original work is properly cited. 